IRA-International Journal of Education \& Multidisciplinary Studies

ISSN 2455-2526; Vol.06, Issue 01 (2017)

Pg. no. 84-100

Institute of Research Advances

http://research-advances.org/index.php/IJEMS

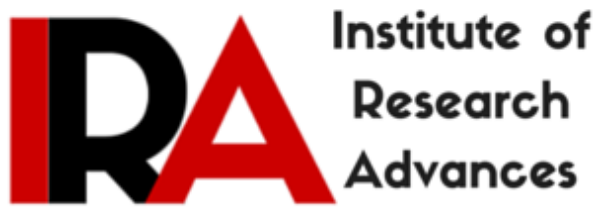

\title{
The Theory of Investment in Schooling
}

\section{Diana Loubaki}

ISG, Department of Economics, University Marien NGouabi, Brazzaville, Republic of the Congo.

Type of Review: Peer Reviewed.

DOI: http://dx.doi.org/10.21013/jems.v6.n1.p6

\section{How to cite this paper:}

Loubaki, D. (2017). The Theory of Investment in Schooling. IRA International Journal of Education and Multidisciplinary Studies (ISSN 2455-2526), 6(1), 84-100. doi:http://dx.doi.org/10.21013/jems.v6.n1.p6

(C) Institute of Research Advances

(c) EY-NC

This work is licensed under a Creative Commons Attribution-Non Commercial 4.0 International License subject to proper citation to the publication source of the work.

Disclaimer: The scholarly papers as reviewed and published by the Institute of Research Advances (IRA) are the views and opinions of their respective authors and are not the views or opinions of the IRA. The IRA disclaims of any harm or loss caused due to the published content to any party. 


\begin{abstract}
The aim of this article is to bring an additional source of countries heterogeneity in the growth literature focused on knowledge accumulation. We find that, the observed heterogeneity in development levels among countries come mostly from income heterogeneities among families as the resulting effect of supplementary investment in schooling provided by parents since the high school. The productivity generated induces the firms' profits increase through technology better comprehension, thus increases the country's economic growth. Therefore, embodied knowledge is a process composed of two steps which are: schooling investment or ex-ante knowledge, first and human capital or ex-post knowledge after, thus are crucial unemployment reduction mechanisms.
\end{abstract}

\title{
JEL CLASIIFICATION: O11; O40; O20; I25; F62; F63
}

Keywords: Ex-ante Human Capital, Ex-post Human Capital, Children Quality, Education, Schooling

\section{INTRODUCTION}

Until today, accounting for countries growth rates heterogeneity around the world, remains a central issue of comparative economic development ${ }^{1}$ in order to understand growth movements over time in the economic literature. The problem began with the impossibility to show where growth came from, since the poor grow faster than the richer countries, thus what causes growth increase? How to determinate the appropriate development strategy for growth enhancing in developing countries?. Those questions led to economic crisis both in development and in growth literatures in the 1970s which ends-up at the middle of the year 1980s for the first and the beginning of the year 1990s for the second, thus also gathered the both theories in one since all the existing barriers among them were levy and yield to endogenous growth literature where growth is the resulting effect of investment in knowledge, human capital and R\&D. Whereas, the economic literature viewed growth on the basis of human capital as growth engine explanation, this article shows that, human capital investment can settled only after a successful primary schooling i.e from the beginning to the high school diploma, thus human capital is measured at the level of specialized studies like university knowledge acquisition and to join the associated microeconomic studies, its accumulation deserves a decision on its cost compare to its benefit. Indeed, before that given time, schooling is settled thus and human capital after since the first is a prerequisite of human capital investment decision. According to Lucas (1988), the individual human capital, $h$ is his general skill level, so that a worker with human capital $h$ is more productive than the one endowed of human capital level, $h / 2$ so that human capital theory focuses on the way an agents allocates his time between good production and education. Indeed, this article adopts the fact that, human capital theory is focused on the way parents invest on their offsprings in order to increase their quality as well as their probability to be able accumulate human capital. Thus, this article gives an answer to Lucas (1988) question on economic development i.e "is there some action a government of India could take that would lead the Indian economy to grow like Indonesia's or Egypt's? If so, what, exactly? If not, what is it about the "nature of India" that makes it so? The consequences for human welfare involved in questions like these are simply staggering: Once one starts to think about them, it is hard to think about anything else"

This article uses France history in order to provide a theory of investing in schooling that we consider to hold from the beginning, to the high school diploma i.e from 6 to 18 years old and may depends on some other influencing variables such that to repeat a given class level.

So that this article aim is to highlight a new way of viewing the problem in bringing new mechanisms able to solve the problem, to really understand the growth rates differentials around the world, this article proposes to go down the real sources of preliminary inequalities in education access relied both to parental investment in the quality of children depending on their own human capital level in order to build theoretical foundations explaining human capital investment over time in a given country,

\footnotetext{
${ }^{1}$ According to Robert Lucas, Jr, 1988, P.1, the problem of economic development is the problem of accounting for the observed pattern, across countries and across time, in levels and rates of growth of per-capita income
} 
thus growth and development level exhibits by the country. To show that, we need to understand first, the history of schooling, to do so, we focus on the French system history through the time to prove that as long as macroeconomic models of education will omit the perquisite necessary for human capital accumulation in the analysis, the differential development paradox among the countries will remain unsolved mostly because human capital is only to the resulting effect of schooling investment in high school first, since some countries and parents don't deserve the same amount of preliminary investment on children quality, development highlight heterogeneity like a fact without real solutions. The model uses the argument that technological progress is the resulting effect of the return to human capital as clearly stated by Theodore W. Schultz $(1960)^{2}$. But consider that, human capital as used by the literature emerges only after the strong basic knowledge acquisition by children who are submitted to the selection process along their schooling period and the remaining or the strongest of them are those who are able to accumulate human capital used in the literature of endogenous growth. Indeed, doesn't follow microeconomic models of human capital where the decision to accumulate human capital is done by the agent himself. Therefore, understanding both income inequalities among families as well as the development differentials among countries, must be placed on children evolution observation through time, indeed doing so, yield both $\mathrm{R} \& \mathrm{D}$ and human capital accumulation having a sense. Therefore, human capital evocated in the literature of growth holds after only, thus is ex-post knowledge rather than ex-ante knowledge. Moreover, when Children acquire knowledge, their level depends on the additional investment done by their parents as already stipulated in the literature. Indeed, rise formal schooling value in economic growth explanation. Indeed, new technology when changing rapidly, deserve the increase of schooling level of investment to face future movements in order to maintain the country's economic growth around its steady state. The scientific contribution of the article holds on several aspects which are first human capital is not the preliminary mechanics of development heterogeneity explanation around the world, second, growth and development heterogeneity among countries are the resulting effect of schooling investment rather that of human capital investment directly, third, development is the resulting effect of all the workers inside the economic system in the activity of wealth creation.

The link between education and technological change was first proposed by Nelson and Phelps (1966). Andrew D. Foster and Mark R. Rosenzweig (1996) find that, technological change during the green revolution in India raised the return to schooling, and that school enrollment rates responded positively to this higher return longevity implicitly affects the weight of the utility from consumption and children is irrelevant for the results. As shown in a previous version of the paper, one could equivalently assume that individuals derive utility from average per period lifetime consumption and children as in Galor and Weil (2000). Indeed, in this paper we finally explain the heterogeneity in countries economic performance, by the children investment in schooling who are submitted by the system action which make the preliminary choices for them and so that, human capital investment can only be done by children who have succeeded to cross those barriers and became student not only by a free decision but also by preliminary holding the required level to follow classes at high training levels such that engineers to generate high quality goods in production when adopting new technology or innovations generation through $\mathrm{R} \& \mathrm{D}$ when working in the research sector as a professor. But that aspect is not enough to explain the formation of growth in a given country. The models thus highlights the fact that investment in schooling is crucial for the economy since it makes the firms of the country remain competitive and the country highlights high growth rates since at any time, technology evolution can be followed by some children whose background is quite high.

The model is a unified growth model where parents spend time evaluate in financial spending to raise their children in order to increase the quality of their schooling, they work and consume also. At the equilibrium, growth rate parameters are relied to those of the background required for children quality, the education system makes a selection at each time to keep the strongest children inside the system so that they can accumulate human capital and give an orientation to the economic performance of the country depending on their quality mainly focused on time spent for their

\footnotetext{
${ }^{2}$ Examining agriculture, Schultz argued that when productive technology has been constant for a long period of time, farmers will have learned to use their resources efficiently
} 
education by their parents, when equal to zero exhibit a poverty trap due to human capital absence, when average, growth progress slowly and development take-off occur and may settle. Finally when time spent for the children quality is high, growth is also high and the children are future labor forces, possess the necessary background to adapt to new innovations introduced in the production sectors. Therefore, poverty in countries is also explained by children low education back ground in contrast to rich countries where it seems to be less strong. Since the results highlighted by the model plays all over the world, indeed countries' category are indexed by $i$ in order to conduct the study on the basis of France education system that we present now since the beginning to capture some mutations occurred as well as understand hypothesis made in the model.

In France, until the middle age i.e from 789 to the $12^{\text {th }}$ century, schooling didn't exist, but knowledge was essentially privately kept in monasteries though which only catholic could access to it. From the $12^{\text {th }}$ century i.e during the "Renaissance", it can be seen a progress in education through the creation of universities and Colleges mainly due to the Greek Authors such that Aristote, Thales, Euclide, Archimede etc, ... but both during the Middle age and the Renaissance, education was conducted in Latin until the years 1530s when some French Authors like Ramuz and Forcadel began to use the French language in education which was closed until then. In 1698, King Louis XIV asks parents to send children to school until the age of 14 years old but the financial aspect of the project was not forthcoming so that the project couldn't hold. Indeed, the most educated proportion of the population was Aristocratic families as well as priests of the Catholic church who could access Latin and Greek languages in contrast to the other part of the population who couldn't because until that time, French was not unified yet the poor agents were essentially using country side languages.

During the 16th and the 17th centuries, the Catholic Religious create some free prestigious high schools like "Lycée Louis le Grand" in Paris but education remains essentially conducted in Latin language which still non accessible for everybody except for children from "bourgeoisie" i.e high non Aristocratic social classes. After the 18th century, the French language began to be taught at school and widen until the beginning of the 1789 revolution when education begins to increase its importance in the lives of the French inhabitants and the will to levy the religious aspect in education. Indeed, in 1791, the first laws of free education began to be proposed by Politicians like Louis Joseph Charlier and public schools began to be introduced as well as the most prestigious French Schools like "Ecole Centrale". Under the reign of Napoleon the first in 1802, are create Imperial Universities in 1806. Under the "Restauration" i.e in 1816, basic education or schooling is introduced for free. During the 19th century, the government will is to improve basic education in cooperation with the Church but unfortunately until the 1848 revolution, none government could make education or schooling compulsory. In 1808, the first important high school diploma is created called "Baccalaureat", which is passed around the age 18 actually. This graduation aim is to close the high school divided in two parts in France which are the secondary and the Tertiary school with length of approximately 7 years today. When its creation was done, only 31 candidates could be accounted, this number turns out to be equal to 878 for Paris in 1885 and 776 for the other parts of the country. Fortunately, in the years 1880, Jules Ferry and Ferdinand Buisson established laws in regard to that aspect i.e schooling became compulsory and laic for all the children until the age 18 years old, but finally that aspect of age was reduced to 16 years old until now by Bethoin. Despite of that, the demand of schooling met the limited supply which yields the system to its fall during the great revolution of 1968. Its refund in order to make a balance between the supply and the demand of education for the system to remain in equilibrium, yields the French system adapts itself several times.

The importance of the "Baccalaureat" diploma holds on the fact that, it opens the doors to High level studies i.e both Universities or Government Engineers prestigious schools like "Polytechnique", "Saint-Cyr" (military schools) and "Central", "Mines", "Pont et Chaussées" (high Nation Engineers), "ENA" (high members of the government or Minsister,..), etc,.. Even if over the time, the demand for those schools became too high so that, it needed some selection with the organization of a kind of preparation at high levels to increase the chances to get a place called "Classes préparatoires" the success remains great.

\footnotetext{
${ }^{3}$ Mathématiques Supérieures (Superior Mathematics), Mathématiques Spéciales (Special Mathematics)
} 
The French system is divided into several directions of training depending on the level hold by the children. At the beginning of the high school, there is an orientation in the second year which allow the system through away all those whose education level is too low to pursue general schooling and go to learn specific jobs low remunerated called, "BEP" and "CAP" and the selection process keeps working until the end of high school so that those who could have escaped those processes remain almost the best candidates for human capital accumulation until the years 1995. So that after 1995, other selection instruments were introduced ("Baccalauréat professionnel" for short training orientation) in order to facilitate employment more efficiently and reduce investment in high level studies since now the selection process keeps working even at the bottom for active selection and the reduction of non realistic demand of education specifically when the government is no more rich enough to wait for failure to occur in restricting the entering of the weak children so that they could invest less and deserve more attention to the children who have the potentiality to follow high level classes and protect them self from non useful investment due to the carry of excess unrealistic choices. Consequently, the system doesn't adopt microeconomic models of the demand of education where the agent decide whether to get inside the education system or not, here government forces highlights by teachers arguments play in order to decide for the young agents to accumulate human capital. The selection engine follows the children from his beginning to his end in education term end along his schooling process, so that parental supplementary education became fundamental for his social position, and the whole represent the mechanics of economic development able to explain countries heterogeneity caused by children heterogeneity since the government will is to reduce schooling investment deficit in the supply of education which must be greatly founded.

So that, accumulate human capital is similar to pursue education after high school validate and creates opportunity costs since it needs investment and gains provided depends mostly on basic background provided by the parents in addition to the government spending. So that, the aim of this article is to highlight the hidden mechanism able to explain income heterogeneity among families, that can also explain countries' growth heterogeneity on the basis of the investment effort done on children through parental financial additional efforts first, which thereby, allow the young agent to choose the direction of training to adopt and accumulate human capital, a by-product of the education sector and generate innovations through $R \& D$ and high tech sectors of productions.

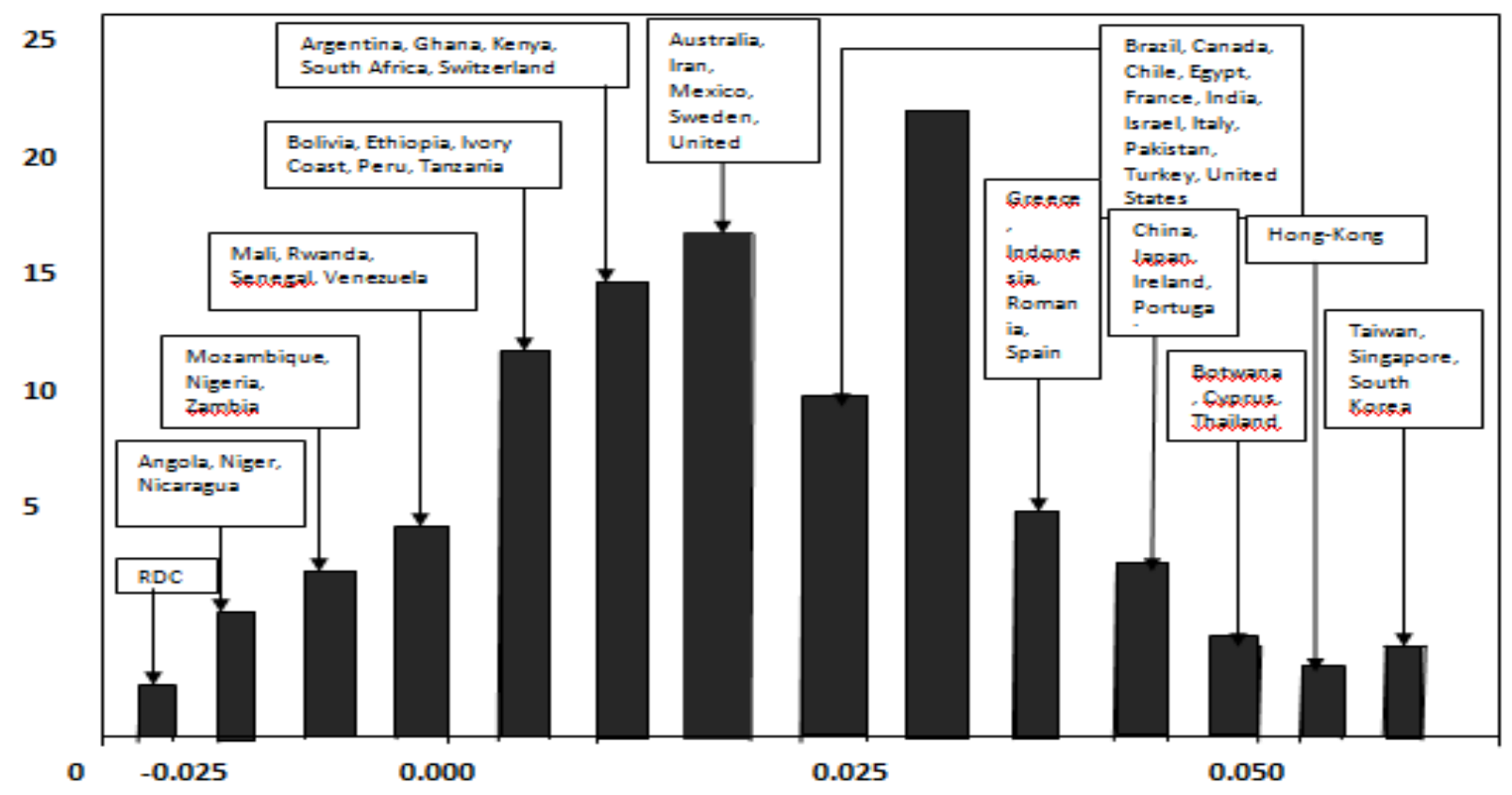

Figure1: Economic growth rates, Source: Barro and Sala-i-Martin, Economic Growth, 2004 


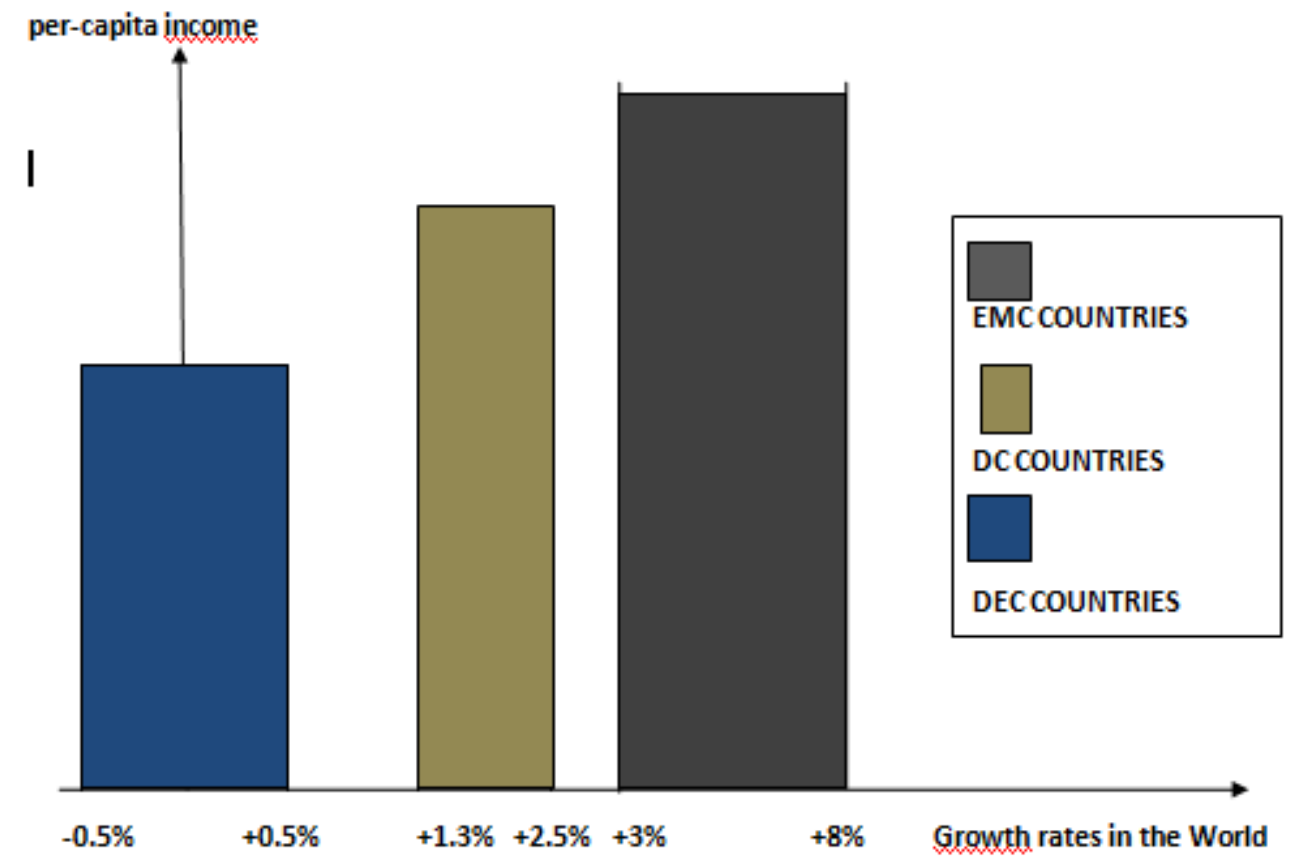

Figure 2: growth rates in DC, DEC and EMC in 2009-2014

The article uses the literature of endogenous growth where human capital accumulation is the engine of growth. The first model to be considered as a growth model is due to Harrod and Domar back to the years 1939 and 1946 respectively. The feature of that model is the fact that it yields to "a knife edge" notion of balanced growth because of the hypothesis of fixity of production factors, then long run growth couldn't hold, thus the theory was assimilated to the short run growth theory. Then Solow (1956) levy the fixity hypothesis of production factors and obtain the long run growth existence and stability but once again in the long run prospect, growth became the same everywhere in the world because of the hypothesis of diminishing returns of marginal capital productivity, the poor countries grow faster than the rich countries and turn out to catch them in economic performance through the convergence mechanism. So that accounting for the observed differences in development term in the world, became a central issue of economic development that the exogenous growth theory was unable to explain since according to the observation ${ }^{4}$, Solow (1956) finding was unable to be proved empirically. Then economists began to look for the sources of economic growth through the mechanism like human capital, technological progress and R\&D. The sources identified were preliminary discovered in microeconomic studies with Theodore Shultz (1960) and Becker (1964) for human capital, technological change generated by R\&D by Schumpeter (1942) with the creative destruction notion specifically adapted in growth analysis by Aghion-Howitt (1992) and pursues by authors like Eicher (1996) and without the creative destruction concept we can find Romer (1990) and the following works like Azariadis-Drazen (1990), establishes the poverty trap existence due to human capital investment absence. Despite of all that, since development and growth literatures are gathered, it can be testified that, they fail to explain the development heterogeneity until now ${ }^{5}$,

\footnotetext{
${ }^{4}$ The diversity accross countries in measured in per-capita income levels is literally too great to be believed. Compared to the 1980 average for what the World Bank calls "the industrial Market Economy. Rtaes of growth of real per-capita GDP are also diverse, for 1960-80, we observe for example: India, 1?4\%; Egypt, 3.4\%, South Korea, 7\%; Japan, 7.1\%; The United Styates, $2.3 \%$, the Industrial economies averaged, $3.6 \%$

5 According to the literature of economic growth, from 1950s to 1960s, economists assume technological progress to occur in an unexplained manner called exogenous (Harrod-Domar, 1948; Solow, 1956). In the 1960 s, growth theory consisted mainly of the neoclassical model based on the optimal saving methodology developed by Ramsey (1928), like Solow (1956), Swan (1956), Cass (1965), and Koopmans (1965). One feature of those models is the convergence property generated. The lower the starting level of real per capita. But those predictions were not confirmed by empirical investigations nor by observations, thus there where a serious
} 
specifically in developing world mainly because, the sources identified are not the roots of the poverty faced there so that, this article aim is to adopt ex-ante and ex-post human capital existence since the both concepts are linked in the way that, the second is the resulting effect of the first. Indeed, this article highlights other mechanisms able to foster growth and development on the basis of the investment done on children during their high school where the decision of their work orientation is taken by the system in function of the investment provided by their parents. Consequently, human capital corresponds only to the little fraction of remaining children who are allow to engage in high skilled labor compare to the whole initial stock. Thus growth and development can't well be explain if a too little part is supposed to exhibit it, indeed yields to the failure of explanation of development retard faced by other countries since the real parameters in action are provided during schooling specifically. Then once integrated, widen the vision of development which deserves more than the government financial support but must be added to parental investment in schooling for human capital theory to exist ${ }^{6}$. Moreover, the production is a coordinated activity between skill and unskilled labors

problem that the theory was unable to explain until the mid 1980s, since then, the research on economic growth experienced a boom, beginning with the work of Romer (1986). The new endogenous growth theories focused now on productivity advances that derive from technological progress and from human capital in the form of education (Lucas, 1988; Barro and Sala-i-Martin (1995) in order to explain the differences among countries in the world. These theories also explore extensions to allow for open economies, diffusion of technology (AghionHowit, 1992), migration of persons (Docquier-Rapoport, 2012), fertility choice (Galor and Weil, 2000)), and variable labor supply (Lucas, 1988). The government can be important in the models in terms of its policies on maintenance of property rights, encouragement of free markets, taxation, education, and health. The concept of capital in the neoclassical model can be usefully broadened from physical goods to include human capital in the forms of education, experience, goods as well as health (Lucas, 1988; Stockey, 1988; Rebelo, 1991; Caballe and Santos, 1993; Mulligan and Sala-i-Martin, 1993; Barro and Sala-i-Martin, 1995a.). One area that has received little attention in the recent literature on growth theory is the relationship between health and economic growth. Two preliminary efforts in this direction are Ehrlich and Lui (1991) and Meltzer (1995). Also, the empirical work of Barro (1996) and others suggests that health status, as measured by life expectancy or analogous aggregate indicators, is an important contributor to subsequent growth. In fact, initial health seems to be a better predictor than initial education of subsequent economic growth. Recent work on endogenous growth theory applies, in particular, to discoveries of medicines or medical procedures (Romer, 1986; Lucas, 1988; Rebelo, 1991)

6 The demand of education is deeply studied in microeconomics models like Mingat (1988), Levy Garboua (1979) and Anderson (1983). According to Anderson (1983), social level of parents depends on their education level, their career and/or their income. Those variables play a great role in the decision on whether to accumulate human capital or not. Mingat(1982) introduces the "failing risk" as a decision variable to invest in education i.e., the agent compares the anticipated benefit of education to the investment cost such that he engages in human capital accumulation only if his probability of success is high enough. Levy Garboua (1979) shows that the demand of education is determined by the comparison between current and future benefit of education. Theoretical macroeconomics model of education include microeconomics decisions to invest in education (Lucas, 1988) and also maximize intertemporal wealth function to determine the endogenous time spent in education (Azariadis Drazen, 1990). In contrast, empirical models of education mostly use the Mincer equation to estimate the impact of some variables of interest on the decision to accumulate human capital (Mankiw Romer Weil, 1992; Park, 1976; Yoo, 1989).

In the exogenous technological change growth model of Stockey (1988), innovations are both accidental and a by-product of learning by doing. In Chari Hopenhayn (1991) model, the diffusion of a specific technology concerns an exogenous technology. Those two frameworks relate human capital investment to an exogenous education production function and decisions of education are thus absents. But our case explicitly shows education function as well as decision to invest in human capital accumulation made by the social planner and show out how human capital investment is acquired. Market based economies lead to inequalities. In contrast, planned based economies bring more equality among economic agents. Since human capital investment deserves no private cost, Eicher (1996) results are ruled-out because market power is reduced by social planner intervention. Young (1993) and Grossman Helpman (1991, ch.5.2) are endogenous growth models with human capital and technological change. Because no explicit decision in education investment is done in those models, movements in terms of relative wages can't be explored. Indeed, since investment decision in human capital accumulation is done by someone else and not by students themself, Stockey (1988), Chari Hopenhayn (1991), Young (1993) and Grossman Helpman (1991, ch.5.2) are validated. Eicher (1996) is also validated for private investment in human capital accumulation through the market price. As stipulated by the literature, human 
for income increase. But the background of the children must be strong enough in order to allow them adapt and absorb new technology produced by new innovations.

The article is presented like follow, section 2 set-up the theoretical model of schooling, section 3 presents the results, section 4 provides the discussion of the model, section 5 concludes on the analysis.

\section{THE MODEL OF INVESTMENT IN EX-ANTE HUMAN CAPITAL}

This section presents the theoretical framework of the theory, we discuss the findings provided in the next section and we conclude on the study after the next section.

\section{Population Structure:}

The world is composed of three countries indexed by $i=D V, D E V, E M C$ which means countries are respectively developed, developing and emerging with differences hold on several aspects which are: their growth rate level, their technological progress and their population size that we precise in the following array in conformity to the data observation.

\section{Table1: country's characteristics}

\begin{tabular}{|c|c|c|c|}
\hline Country's characteristics & DEV & DV & EMC \\
\hline Population size & Small & Average & Very large \\
\hline Growth rate & Low & High & Very high \\
\hline Development level & Low & High & Above the average \\
\hline
\end{tabular}

Source: Data observation around the World in The World Bank Development Report, 2013 and summarized qualitatively

The three economies are composed of overlapping generation agents who live for two periods in each country, there are: the childhood and the adulthood period. The length of the first period is $K_{t}^{i}=k^{i}$ and adulthood has a duration, $T_{t}^{\mathrm{i}}$ and each individual of generation $t$ survives with probability $\pi_{t}^{i} \in(0,1)$. Surviving children become adults and survive with certainty until the age $k^{i}+T_{t}{ }^{\mathrm{i}}$ and then die. The variable $T_{t}{ }^{i}$ represents both life expectancy at age $k^{i}$ and the maximum duration of adulthood and can also be interpreted as a "health augmented" time endowed of adults.

According to table1, we have: $\operatorname{Min}\left(k^{i}+T_{t}^{\mathrm{i}}\right) \operatorname{CDEV}<A v e\left(k^{i}+T_{t}^{\mathrm{i}}\right) \operatorname{CDV}<\operatorname{Max}\left(k^{i}+T_{t}^{\mathrm{i}}\right) \in \mathrm{EMC}$ is the average life expectancy, in each of those countries indexed by $i$. In economic performance measured by the

capital can be accumulated through several channels and financial supports. Relative wages increase lead to both students and higher skilled professor stocks increase.

Therefore, the system increases its capability to lift up the economy out of the poverty trap in which it is kept.

The AK models of Romer (1986), Lucas (1988) and King-Rebelo (1987) implicitly mixed knowledge that can survive in somebody or human capital to physical capital and/or to knowledge contains in supports such as books.

Grossman Helpman (1991, Ch.5.2) makes both human capital and technological change endogenous but assume incentives to accumulate human capital not related to technology absorption cost which is relative wages in our consideration. Maksymenko Rabbani (2011) shows that human capital as positive effects on economic development both in South Korea and in India.

The results of Eicher (1996) come from Mincer (1994) where relative wages and skilled labor move in the opposite direction at least since 1963. Specifically, Eicher (1996) analysis is based on the 1980' observations and finds that, the biased on the skilled labor demand is explained by higher relative wages movements because the absorption of innovations needs the skilled labor demand increase which is low because of its cost. To solve the paradox of the skilled labor supply decrease and relative wages increase, Mincer uses the direct cost of education as the determinant of the labor supply and finds a negative correlation among them since at least 1967. Because poor country is far from his technological frontier, benefit of investing in high education is not interesting enough (Aghion and Cohen, 2004). That is why most of the studies of education in economic development mostly focus on basic labor training 
level of development ${ }^{7}$, according to the data the classification made is: $D E V<E M C<D V$, in growth rates measured by the GDP, it can be considered that we have is: $D E V<D V<E M C$.

Reproduction takes place at $m^{i} \geq k^{i}$ which is the length of a generation. At each period, enter a stock of $N_{t}^{\mathrm{i}}$ young people who decide whether to engage in education at the end of the beginning of their second period and attain a human capital level, $h_{t}{ }^{\mathrm{i}}$ to both absorb and adapt new methods in the production sector as engineer or professor to generate innovations through $\mathrm{R} \& \mathrm{D}$ or in production and keeps his innate ability, $a$, at the beginning of their second period. Population size moves such that $N_{t+1}{ }^{i}=\pi_{t}{ }^{i} n_{t}{ }^{i} N_{t}{ }^{i}$ where $n_{t}{ }^{\mathrm{i}}$ is the average fertility rate and $\pi_{t}^{i}$ is the survival probability. Each individual of the cohort $t$ is endowed of innate ability $h(a)^{8}$

\section{Preferences}

At the beginning of adulthood, the child who have survived childhood makes his decisions about his own, consumption, health state through insurance acquisition and their fertility to maximize their remaining life time utility first and see whether going to the education system or not. The lifetime utility function is therefore given by equation (1) in each country, $i$ such that:

$\int_{0}^{T_{t}}\left[\ln \left(c_{t}^{i}(\tau)\right)+\beta^{i} \ln \left(s_{t}^{i}(\tau)\right)+\gamma^{i} \ln \left(\pi_{t}^{i} n_{t}^{i} q_{t}^{i}\right)\right] d \tau$

Where $0<\beta^{i}, \gamma^{i}<1$ are the respective elasticity of insurance and the weight of the utility that parents derive from their living children relative to their own life in regard to their own lifetime consumption and health as adult, $s_{t}^{i}$ is insurance for health care; $\pi_{\mathrm{t}}{ }^{\mathrm{i}} \mathrm{\epsilon}(0,1)$ is the probability for surviving children to become adults, $n_{\mathrm{t}}^{\mathrm{i}}$ is the average gross fertility of the parent cohort, $q_{\mathrm{t}}^{i}$ is the quality of offspring $\pi{ }_{\mathrm{t}}^{\mathrm{i}} n_{t}^{i}$ in the country $i$,

The budget constraint of the agent of the country $i$ can be written such that:

$$
T_{t}^{i}\left(c_{t}^{i}+s_{t}^{i}\right)=\left(\bar{T}_{t}^{i}-\underline{e}_{t}^{j}-\pi_{t}^{i} n_{t}^{i} t_{t}^{i}\right) w_{t}^{i, j} h_{t}^{i, j}(a)
$$

Where $i=D E V, D V, E M C ; j=$ skilled and unskilled labors; $\bar{T}_{t}^{i}=\min \left\{\mathrm{T}_{\mathrm{t}}{ }^{i}, R_{t}{ }^{i}\right\}$ and $\underline{e}_{t}{ }^{j}{ }^{j}$ are the respective effective minimum time available for productive activities during adulthood and a fixed cost measure in term of adult time where $R_{t}^{i}>0$ is the retirement period in country $i$ and $T_{t}^{i}$ is the time available during adulthood or adult longevity, $r_{t}^{i}$ is time cost for raising child expressed such that, $r_{t}^{i}=\hat{r}_{t}^{i}+\underline{r}_{t}^{i}$ with $\underline{r}_{t}^{i} \succ 0$ a fixed time cost that need to be spent in charge of the government in the $\wedge^{i}$

schooling program for children, $r_{t} \geq 0$ is the additional time spent by the parents measured in terms of cost for schooling level improvement. It is spent voluntarily in addition by the parents in country $i$.

The maximization of the intertemporal utility function leads to compute the Lagrangian which can be written such that:

$$
\begin{aligned}
\Pi=\int_{0}^{T_{t}}\left[\ln \left(c_{t}{ }^{i}(\tau)\right)+\ln \left(s_{t}{ }^{i}(\tau)\right)+\gamma^{i} \ln \left(\pi_{t}^{i} n_{t}^{i} q_{t}^{i}\right)\right] d \tau \\
\quad+\lambda^{i}\left[T_{t}^{i}\left(c_{t}^{i}+s_{t}^{i}\right)-\left(\overline{T^{i}}{ }_{t}-\underline{e}_{t}^{j, j}-\pi_{t}^{i} n_{t}^{i} t_{t}^{i}\right) w_{t}^{i, j} h_{t}^{i, j}(a)\right]
\end{aligned}
$$

The first order conditions are given by the following expressions:

$$
\partial \Pi / \partial c_{t}^{i}=0 \Rightarrow 1 / c_{t}^{i} T_{t}=\lambda T_{t}^{i}
$$

\footnotetext{
${ }^{7}$ See the World Bank Countries Classification

${ }^{8}$ during his childhood which is randomly drawn from a distribution $f(a)$ where $a \rightarrow N(E(a), \sigma)^{8}$

${ }^{9}$ In Cervellati and Sunde (2015), the weight of the utility of the children is outside the integral and insurance acquisition for health care is not discussed
} 


$$
\begin{aligned}
& \partial \Pi / \partial s_{t}^{i}=0 \Rightarrow 1 / s_{t}^{i} T_{t}=\lambda T_{t}^{i} \\
& \partial \Pi / \partial n_{t}^{i}=0 \Rightarrow \gamma^{i} / n_{t}^{i}=\lambda\left(r_{t}^{i} \pi_{t}^{i}\right) w_{t}^{i, j} h_{t}^{i, j}(a) \\
& \partial \Pi / \partial \lambda^{i}=0 \Rightarrow T_{t}\left(c_{t}^{i}+s_{t}^{i}\right)=\left(\bar{T}_{t}-\underline{e}_{t}^{j}-\pi_{t}^{i} n_{t}^{i} t_{t}^{i}\right) w_{t}^{i, j} h_{t}^{i, j}(a)
\end{aligned}
$$
i.e:

Therefore, we determinate the optimal values which are expressed by equations (4) and (5)

$$
\begin{aligned}
& c_{t}^{i}=s_{t}^{i}=\frac{1}{\gamma^{i}}\left(\frac{\gamma^{i}}{2-\gamma^{i}}\right)\left(\bar{T}_{t}^{i}-\underline{e}_{t}^{j}\right) w_{t}^{i, j} h^{i, j}(a) \\
& n_{t}^{i}=\left(\frac{\gamma^{i}}{2-\gamma^{i}}\right)\left[\frac{\bar{T}_{t}^{i}-\underline{e}_{t}^{i}}{r_{t}^{i} \pi_{t}^{i}}\right]
\end{aligned}
$$

Equations (4) and (5) mean that per-capita consumption and per-capita insurance for health maintenance deserve the same amount of effort equivalently it means that health state and food have fundamentally the same value. In contrast, the number of children in country $i$ depends on the utility deserved to children in each country as well as the ratio of the difference between the adult longevity and the fixed cost of raising children in term of time spent and the product of the child survival probability and the time cost of raising children. Hence, according to data and the calibration provided by Cervelatti and Sunde (2015), children deserve less attention in developing countries in terms of time spent but provide high utility weight to the parents because of the quantity which is higher than the quality in contrast to most of the developed countries and some of the emerging countries where population size is high currently but policies to reduce it are commonly used ${ }^{10}$.

\section{The Exogenous Schooling Sector of Education}

The quality of the level of schooling reached by the children increases in function of time spent according to:

$$
q_{t}^{i}\left(\underline{r}_{t}^{i}, \hat{r}_{t}^{i}, g_{t+1}^{i}\right)=\left[\hat{r}_{t}^{i} \theta^{i}\left(1+g_{t+1}^{i}\right)+\underline{r}_{t}^{i}\right]^{\varepsilon^{i}}
$$

Where

$g_{t+1}{ }^{i}=\frac{A_{t+1}^{i}-A_{t}^{i}}{A_{t}^{i}}$ is technological progress growth rate and $\varepsilon^{i} \in(0,1), \quad \theta^{i} \succ 0$ are the respective elasticity of the quality of education or schooling given to children and the weight of quality of schooling in the country $i$. Raising a child involves a time cost $r_{t}^{i}=\hat{r}_{t}^{i}+\underline{r}_{t}^{i}$, where $\underline{r}_{t}^{i} \succ 0$ is a fixed time cost spent by the government education policy and $\hat{r}_{t}^{i} \geq 0$ is the extra time spent voluntarily in by the parents who are able to increase their children basic background in addition.

\footnotetext{
${ }^{10}$ See China family planning

${ }^{11}$ This equation is the one used by Cervellati and Sunde (2015) to highlight the fact that the quality of the children is linked to the one of the technological progress of the country specifically in the future. The same idea is used by Galor and Weil (2000). If the quality of the children is viewed such that a ratio, then the quantity of the children mostly viewed in developing countries can be considered such as the opposite and may be considered such that, quantity is expressed like: $1-q($,
} 


\section{The Education Sector}

The agent who could have chosen to become skilled is endowed at a certain time of his adulthood of a human capital level, $h_{t}^{i, s}(\mathrm{a})$ in the country $i$ which depends on the country's technological level plus an additional knowledge, $A_{t}^{i}$ after having spent time in the education sector and he becomes professor who generate innovations through research or Engineer in the production sector where he absorbs and/ or adapt new production methods. In contrast, the agent who couldn't have chosen to become skilled, remains unskilled endowed of an ability level, $h_{t}^{i, u}(\mathrm{a})=h^{i}(a)$ and performs routine tasks both in education sector and in production sector for the same wage rate income. The production sectors are divided in two fields which are the low and the high tech sectors to manage the same homogeneous consumption goods.

The education sector is exogenously specified, student stock, $S_{t}^{\mathrm{i}, \mathrm{j}}$ are in the second period endowed with per-capita human capital level, $h_{t}^{i, s}$ then he becomes engineer, $S_{t-l}{ }^{\mathrm{i}, \mathrm{j}}=E_{t}^{\mathrm{i}, \mathrm{j}}$ and work in the production sector or professor, $P_{t}^{i, j}$ who generate new innovations through R\&D in the research sector. Unskilled labor stock is, $U_{t}^{i, j}$ such that $U_{t}^{H, j}+U_{t}^{\mathrm{L,j}}=U_{t}^{j}$ and the whole labor stock is such that $U_{t}^{i, j}+S_{t}^{i, j}=1$. Because the article mostly focused on schooling evolution acquired through parental human capital investment, we assume an exogenously specified education sector in order to close the issues related to parents' education. More precisely, the analysis chooses to promote quality in the choice as well as in the schooling of the children to anticipate future economic performance of the countries, the study closely related to sociological studies which specify that children mostly inherit of their parent skills over time ${ }^{12}$

\section{The Production Sector}

The production sector produces one homogenous consumption good with labor heterogeneity, there exist high tech and low tech production sectors which respectively absorb and adapt new innovations in good production and the other which performs routine tasks once the technology is discarded and left to unskilled labor ${ }^{13}$. Following Eicher (1996), the high tech sector of production function of the country $i$ can be expressed such that equation (7) i.e

$$
H_{t}^{i}=A_{t}^{i}\left(U_{t}^{i, H}\right)^{\alpha}\left(E_{t}^{i, j}\right)^{1-\alpha}
$$

Where $j=H, U$

The low tech sector of production function can be expressed such that equation (8) i.e

$$
L_{t}^{i}=\eta_{t}^{i} A_{t-1}^{i} U_{t}^{i, H}
$$

Where $A_{t-1}{ }^{i}$ is technology of period $t-1$; $U_{t}^{i}$ for $i=H, L$ are the respective unskilled labor of the high and the low tech sectors where $U_{t}^{L, j}+U_{t}^{H, j}=U_{t}^{i}$ for country $i$ and $\eta_{t}^{i}>1$ is the productivity of the unskilled labor

Maximization of the production functions yields the standard first order conditions expressed by equations (9)-(11) i.e

$$
\begin{aligned}
& w_{t}^{H, S}=(1-\alpha) A_{t}^{i} e_{t}^{\alpha} \\
& w_{t}^{H, U}=\alpha A_{t}^{i} e_{t}^{\alpha-1} \\
& w_{t}^{L, U}=\eta_{t}^{i} A_{t-1}^{i}
\end{aligned}
$$

Where $e_{t}^{i}=U_{t}^{i, H} / E_{t}^{i, j}$

The factor market prices yields

$$
\begin{aligned}
& w_{t}^{H, S}=w_{t}^{P} \\
& w_{t}^{H, U}=w_{t}^{L, U}
\end{aligned}
$$

Equation (12) means that the wage rate income as engineer in the production sector is the same as professor in research and development sector. Similarly, equation (13) means that, unskilled labor in the production sector and in education wage rate income are the same.

\footnotetext{
${ }^{12}$ Bourdieu, les Héritiers

${ }^{13}$ This is a concept of creative destruction due to Schumpeter (1942)
} 
Using equations (10) and (11) as well as equation (13) yields $w_{t}^{H, U} / w_{t}^{L, U}=1$ then we obtain $\frac{A_{t}^{i}}{A_{t-1}^{i}}=\frac{\eta_{t}^{i}}{\alpha} e_{t}^{1-\alpha}$ consequently, we have $g_{t+1}{ }^{i}=\frac{A_{t+1}^{i}-A_{t}^{i}}{A_{t}^{i}}=\frac{\eta_{t}^{i}}{\alpha} e_{t}^{1-\alpha}-1>0$

\section{Human Capital Growth rate}

Technological progress takes place with the emergence of new innovations, $A_{t}^{\mathrm{i}}$ and the amount of human capital stocks expressed by the sum of engineers and professors i.e $E_{t}^{i}+P_{t}^{i}=S_{t-1}{ }^{i}$ such that

$$
\Delta S_{t}^{i}=\frac{S_{t+1}^{i}-S_{t}^{i}}{S_{t}^{i}}
$$

Equation (14) means that, for any innovation, improvements are smaller as $\Delta \mathrm{S}_{t}^{\mathrm{i}}$ converges to 0 because current and future human capital stocks remain the same it is becoming greater when future human capital stock is greater than current human capital stock.

Definition1: the interaction between human capital accumulation and technological change is defined by the locus on the space where they move at the same rate i.e

$$
g_{t+1}{ }^{i}=\frac{A_{t+1}^{i}-A_{t}^{i}}{A_{t}^{i}}=\Delta S_{t}^{i}=\frac{S_{t+1}^{i}-S_{t}^{i}}{S_{t}^{i}}
$$

\section{RESULTS}

Proposition1: the endogenous time cost of raising children is expressed such that

$$
r_{t}^{i}=\frac{\gamma^{i}\left(\bar{T}_{t}^{i}-\underline{e}_{t}^{i}\right) \alpha}{\eta_{t}^{i}\left(2-\gamma^{i}\right) e_{t}^{1-\alpha}}
$$

Proof: according to definition1, the growth rate depends on human capital growth rate expressed above and moves at the same rate as population growth rate such that

$$
g_{t+1}^{i}=\frac{\eta_{t}^{i}}{\alpha} e_{t}^{1-\alpha}-1=\frac{N_{t+1}^{i}-N_{t}^{i}}{N_{t}^{i}}=\pi_{t}^{i} n_{t}^{i}-1^{14}
$$

Which yield

$$
\pi_{t}^{i}=\frac{\eta_{t}^{i}}{n_{t}^{i}} \frac{e_{t}^{1-\alpha}}{\alpha}
$$

Using equation (5) of optimal fecundity rate i.e

$n_{t}^{i}=\left(\frac{\gamma^{i}}{2-\gamma^{i}}\right)\left[\frac{\bar{T}_{t}^{i}-\underline{e}_{t}^{i}}{r_{t}^{i} \pi_{t}^{i}}\right]$ inside the previous equation, it yields $\pi_{t}^{i}=\frac{\eta_{t}^{i}\left(2-\gamma^{i}\right)}{\gamma^{i}\left(\bar{T}_{t}^{i}-\underline{e}_{t}^{i}\right)} \frac{r_{t}^{i} \pi_{t}^{i} e_{t}^{1-\alpha}}{\alpha}$

Therefore we obtain the endogenous form of time cost of raising children expressed such that

$$
r_{t}^{i}=\frac{\gamma^{i}\left(\bar{T}_{t}^{i}-\underline{e}_{t}^{i}\right) \alpha}{\eta_{t}^{i}\left(2-\gamma^{i}\right) e_{t}^{1-\alpha}}
$$

Definition2: the transitional equilibrium is the locus on the space where the variables of consumption and health state move at the same constant rate equal as the final growth rate i.e where

\footnotetext{
${ }^{14}$ In the model of Arrow and its elaborations by Levhari (1966a, 1966b) and Sheshinski (1967), it is assumed that output as a function of capital and labor, exhibits increasing returns to scale but that the marginal product of capital is diminishing given a fixed supply of labor. As a result, the rate of growth of output is limited by the rate of growth of the labor force. By identifying the population growth rate to the labor force, thus we assume that full employment is perpetually maintained (Solow, 1956).
} 
$\frac{c_{t+1}^{i}-c_{t}^{i}}{c_{t}^{i}}=\frac{s_{t+1}^{i}-s_{t}^{i}}{s_{t}^{i}}=g_{t+1}^{i}$ where human capital depends on the quality of education given by equation $(6)^{15}$ since the quality of children depends on the time cost for raising children, i.e $g_{t+1}^{i}=r_{t}^{i} q_{t}^{i}\left(r_{t}^{i}\right)$

Proposition2: For the elasticity of the quality of education, $\varepsilon^{i}$ such that $0<\varepsilon^{i} \leq 1$, the economic performance expressed in growth rate in the globalized economy depends on schooling related to technological progress such that, it is an increasing function of the fixed cost that need to be spent, $\underline{r}_{t}^{i}$

, the weight of quality in the country's performance evolution, $\theta^{i}$ the extra time that can be spent, $\hat{r}_{t}$ the effective minimum time available for productive activities during adulthood, $\bar{T}_{t}^{i}$ the weight of the utility that parent deserve from their living children, $\gamma^{i}$ and of the fraction of human capital in production. It is therefore, a decreasing function of the low tech sector efficiency, $\eta_{t}^{i}$ of the ratio of unskilled to skilled labor, $e_{t}$ and of fixed cost measured in terms of adult time, $\underline{e}_{t}^{i}$ therefore, future generation education is able to predict the evolution of the economy over time

Proof: according to definition2, the transitional equilibrium in growth rate can be expressed such that

$$
\begin{aligned}
& g_{t+1}^{i}=r_{t}^{i}\left[\hat{r}_{t}^{i} \theta^{i}\left(1+g_{t+1}^{i}\right)+\underline{r}_{t}^{i}\right]^{\varepsilon^{i}} \text { which yields to the following expression } \\
& \left(\frac{1}{r_{t}^{i}}\right)^{1 / \varepsilon^{i}}\left(g_{t+1}^{i}\right)^{1 / \varepsilon^{i}}=\hat{r}_{t}^{i} \theta^{i}\left(1+g_{t+1}^{i}\right)+\underline{r}_{t}^{i}
\end{aligned}
$$

Introducing equation (17) inside the above expression and seting, $\varepsilon^{i}=1$, we find an equation expressed such that

$$
g_{t+1}^{i}=\frac{\hat{r}_{t}^{i} \theta^{i}+\underline{r}_{t}^{i}}{\left[\frac{\eta_{t}^{i}\left(2-\gamma^{i}\right) e_{t}^{1-\alpha}}{\gamma^{i}\left(\bar{T}_{t}^{i}-\underline{e}_{t}^{i}\right) \alpha}\right]-\hat{r}_{t}^{i} \theta^{i}}
$$

Differentiating the equation below in function of all its parameters, we find that: the transitional growth rate of the three kinds of countries is an increasing function of the fixed cost that need to be spent, $\underline{r}_{t}^{i}$, the weight of quality in the country's performance evolution, $\theta^{i}$ the extra time that can be spent, $\hat{r}_{t}{ }^{i}$ the effective minimum time available for productive activities during adulthood, $\bar{T}_{t}^{i}$ the weight of the utility that parent deserve from their living children, $\gamma^{i}$ and of the fraction of human capital in production. It is therefore, a decreasing function of the low tech sector efficiency, $\eta_{t}^{i}$ of the ratio of unskilled to skilled labor, $\mathrm{e}_{\mathrm{t}}$ and of fixed cost measured in terms of adult time, $\underline{e}_{t}^{i}$ Doing the same thing for $0<\varepsilon<1$ and replacing $r_{t}^{i}$ by its value given by equation (17) it yields the following expression

\footnotetext{
${ }^{15}$ Cervellati and Sunde (2015) used the following equation $g_{t+1}^{i}=n_{t}^{i} q_{t}^{i}$
} 


$$
g_{t+1}^{i}=\left(\frac{\gamma^{i}\left(\bar{T}_{t}^{i}-\underline{e}_{t}^{i}\right) \alpha}{\eta_{t}^{i}\left(2-\gamma^{i}\right) e_{t}^{1-\alpha}}\right)\left(\hat{r}_{t}^{i} \theta^{i}+\underline{r}_{t}^{i}\right)^{\varepsilon^{i}}\left(1+\frac{\hat{r}_{t}^{i} \theta^{i}}{\hat{r}_{t}^{i} \theta^{i}+\underline{r}_{t}^{i}} g_{t+1}^{i}\right)^{\varepsilon^{i}}
$$

Because around zero we can make the following approximation

$$
\left(1+\frac{\hat{r}_{t}^{i} \theta^{i}}{\hat{r}_{t}^{i} \theta^{i}+\underline{r}_{t}^{i}} g_{t+1}^{i}\right)^{\varepsilon^{i}} \approx 1
$$

Indeed the previous equation can be approximated such that

$$
g_{t+1}^{i}=\left(\frac{\gamma^{i}\left(\bar{T}_{t}^{i}-\underline{e}_{t}^{i}\right) \alpha}{\eta_{t}^{i}\left(2-\gamma^{i}\right) e_{t}^{1-\alpha}}\right)\left(\hat{r}_{t}^{i} \theta^{i}+\underline{r}_{t}^{i}\right)^{\varepsilon^{i}}
$$

Differentiating the equation below in function of all its parameters, we find that: the transitional growth rate of the three kinds of countries is an increasing function of the fixed cost that need to be spent, $\underline{r}_{t}^{i}$, the weight of quality in the country's performance evolution, $\theta^{i}$ the extra time that can be spent, $\hat{r}_{t}$ the effective minimum time available for productive activities during adulthood, $\bar{T}_{t}^{i}$ the weight of the utility that parent deserve from their living children, $\gamma^{i}$ and of the fraction of human capital in production. It is therefore, a decreasing function of the low tech sector efficiency, $\eta_{t}^{i}$ of the ratio of unskilled to skilled labor, $\mathrm{e}_{\mathrm{t}}$ and of fixed cost measured in terms of adult time, $\underline{e}^{i}$.

\section{DISCUSSION OF THE MODEL}

Recalling that the general growth rate expression is given by the following equation

$$
g_{t+1}^{i}=\left(\frac{\gamma^{i}\left(\bar{T}_{t}^{i}-\underline{e}_{t}^{i}\right) \alpha}{\eta_{t}^{i}\left(2-\gamma^{i}\right) e_{t}^{1-\alpha}}\right)\left(\hat{r}_{t}^{i} \theta^{i}+\underline{r}_{t}^{i}\right)^{\varepsilon^{i}}
$$

Where

$\underline{r}_{t}^{i}$ is per-capita public investment in schooling; $\hat{r}_{t}^{i}$ is per-capita investment done by the parents which induces a velocity in knowledge beneficial for the whole country measured by $\theta^{i}$ indeed, private investment in schooling is the preliminary foundation of human capital or child knowledge able to generate high level employment

If $\hat{r}_{t}^{i} \leq \underline{r}_{t}^{i}{ }^{16}$ then children are unable to accumulate human capital i.e high level skills, the child will be put out of the system quite soon to be train for a non skilled poor job and perpetuate the lowest social classes with income reduction and growth is negatively affected by that human capital formation impossibility, indeed optimal growth in rate is unable to be reached. Moreover if the stock of human capital absence is too high, then growth regresses and under development pursue until it reaches the poverty trap and highlights retards since $\theta^{i}$ can't be observable. This case can be assimilated to the African Countries where quality in schooling is not high enough for the country to increase its economic performance faster.

Otherwise

\footnotetext{
${ }^{16}$ This case illustrate which one where the high education system is composed of elites properly chosen and to few to make the economy take-off, thus it remains underdeveloped and kept in a poverty trap in conformity with the literature of growth
} 


\begin{abstract}
If $\hat{r}_{t}{ }^{i}=\underline{r}_{t}^{i}{ }^{17}$ then the economic system still doesn't contain enough skilled labor, due to the departure pretty soon of the children from the general school to learn quite fast a job, thus don't access high level studies. Therefore, growth fluctuates around its initial level without improvements since too few investment is deserved to children i.e the level required to accumulate human capital is too low for R\&D to be conducted because it will be too costly to buy high technological equipment in the context of scarcity of users for it to be profitable. Growth rate remains below the average and may reach zero or decrease more because of the lack of skills labor needed by the system for its viability to hold and perpetuates. This fact highlights a kind of marginal decrease of skills over time. This case can be referred to intermediary countries in economic performance such as Latin American countries where the growth path approaches the middle without reaching its development frontier.
\end{abstract}

Finally if $\hat{r}_{t}^{i}>\underline{r}_{t}^{i}$ t8 then human capital formation hypothesis holds in a close future, $\theta^{i}$ holds and skills labor are able to compensate the needs of the whole economy. R\&D can be conducted at low prices since the conditions of its adoption are filled. Growth tends to increase and labor tends to be absorb by the need since it is possible to conduct training depending on the needs because the background hold by the children are enough for them to understand the new technology and increase the competition of the firms. Consequently, the nation growth rate measured by the GDP still increasing, this case can be assimilate to the Industrial countries as well as some Asian countries which exhibit high economic performance such as South Korea, Singapoor, Hong-Kong and Japan in addition to the OECD countries.

To conclude on the action of this first variable, at the state stipulated, it is risky to engage in Western countries technology transfer in Africa since the background required to handle the new technology is absent.

For the variables which actions are not strong enough to push the economic path to development like $\eta_{t}^{i}$ and $e_{t}^{i}=U_{t}^{i, H} / E_{t}^{i, j}$ i.e the importance of low sector production like agriculture rather than industry or manufacture, the system exhibits excess labor demand which needs to be transfer to the modern sector but couldn't because of training non sufficient. That policy was first proposed by Lewis (1954) who forgot to introduce training in new production methods needs for the transfer to hold and excess labor to be eradicated. Excess unskilled labor presence in the system blocks development since possible adaptation is unable to be engaged, thus the country remains in the agricultural level or natural resources international trade which returns are not high enough to develop the industry since markets are absent. The economy exhibit high unemployment and low wage rate income since growth creation mechanisms can't play to boost the economy toward development takeoff.

If the utility the parents derive from their offspring, $\gamma^{i}$ is oriented toward schooling acquisition in order to increase the quality of their offspring, then the economy is boosted. Otherwise if it is more focused on the purpose of supplement income while in resting when old, then growth regresses and the economy records development retard since the children achievement is closely relied to their parents schooling investment explaining the country's economic performance through knowledge accumulated in the high school first.

But those results must be normalized in such a way that, parents are not always able to invest more than they can. To see that, we take the last variables series i.e $\bar{T}_{t}^{i}-\underline{e}_{t}^{i}$ which are respectively the effective available time for productive activity which ensure the household income with the fixed cost measured in terms of adult fixed cost. Those variables are relied in such a way that, we can't have $\bar{T}_{t}^{i} \leq \underline{e}_{t}^{i}$ which means that all the household income is devoted to the children education, thus non realistic and impossible. Consequently, the children social status not only depends on the investment

\footnotetext{
${ }^{17}$ The case corresponds to the one evocated when the whole children are pushed away from the general system to follow little training for job acquisition, unskilled and low paid in France

${ }^{18}$ This case highlights the system where high Government schools are filled and Universities are making the strongest children acquire high education in the case of France exposed earlier
} 
done by his parents, but that investment is relied to the parents' income or social status too. Therefore, we return back to the fact that the children in fine inherit from their parents' status. This fact means that, there is inequality in the world system since the childhood. To fight against that and open more possibility to the children whom parents are unable to afford more than their income on their education, the government programs should be enlarges in the direction of more equality? How can it be done?

\section{CONLUSION}

We have presented a model in which parents invest in schooling for their children in addition to the one provided by the government. But because children face the system selection they are progressively push out of the general system to learn a specific job and the rest invest in human capital and have the highest remunerated jobs, then human capital emerges in the explanation of growth heterogeneity among countries. The success of the children depend on the investment done by their parents since the government aid is not enough to cover the least social classes from poverty and unemployment. Therefore, the real parameters able to explain heterogeneity among countries in growth performances come from schooling or ex-ante human capital since high school and the whole are able to explain how to render a given country as efficient as another one. In parallel, with the endogenous growth model, in the debate of the sources of the country's heterogeneity, the literature provided the brain drain theory in the years 60 with Grubel and Scott (1966) where finally, the purpose of increase of the skilled labor stock turned out to create eviction due to the non return of the former elite from developing countries. But the theory ignore that the real growth providers were the children future, so that training as well as schooling could have been conducted at home because the phenomenon became unsustainable since the losses became too great for the little countries development prospects. The fall of the theory in the first decade of the years 2000 s caused by multiple mutations occurred in Western Countries specifically low growth associated to high unemployment yield to the emergence of the cease of labor mobility between the North and the South as well as refugee mobility crisis faced by Western countries. So that, this theory is a good teller of the appropriate policy to conduct for development to take-off and growth to accelerate in poorest countries since the policy proposed is based on Industrial countries system that can be easily tried in poorest countries. Finally, the article gives an answer to the Lucas (1988) article question presented in the general introduction of the article.

\section{REFERENCES}

1. Acemoglu, D. (2005): Institutions and Growth, in Aghion, P. and Durlauf, S., eds.: Handbook of Economic Growth, North Holland.

2. Azariadis, C. and Drazen, A., (1990): Threshold externalities in economic development, Quarterly Journal of Economics, 501-526.

3. Barro, R. and Sala-i-Martin, X, 2004, Economic Growth, MIT Press

4. Cervellati, M. and Sunde, U. 2015, The Economic and Demographic Transition, Mortality and Comparative Development, American Economic Journal,

5. Domar, E. D., (1946), Capital Expansion, Rate of Growth and Employment, Econometrica, 49, p.1433.

6. Denison, E. F. (1962). "Sources of Growth in the United States and the Alternatives Before Us." Supplement

7. Paper 13. New York: Committee for Economic Development.

8. Dora, Costa, L., 2015, Health and the Economy in the United States From 1750 to the Present, Journal of Economic Literature, 53(3),

9. Easterly, W., 2009, Can The West Save Africa?, Journal of Economic Literature, 47(2), 373447

10. Eicher, T., (1996), Interaction between endogenous human capital and technological change, Review of Economic Studies, 63, 127-144 
11. Galor, O., and Weil, David N. (2000). "Population, Technology, and Growth: From Malthusian Stagnation to the Demographic Transition and Beyond." American Economic Review, 90, September, 806-828.

12. Harrod, R. F., (1939), An Essay in Dynamic Theory, Economic Journal, 49, p.14-33

13. Loubaki, D., 2015, Comparative Economic Development, Brain Drain and Modern Growth, "International Journal of Economic Theory and Application", 2(5), 40-55

14. Lucas, R. E., Jr. 1988. "On the Mechanics of Economic Development." Journal of Monetary Economics 22 (1): 3-42.

15. Romer, P.M. (1986): Increasing returns and long-run growth, Journal of Political Economy, 94, 5: 1002-37.

16. Romer, P. M., 1990. "Endogenous Technical Change.” Journal of Political Economy 98 (5, Part 2): S71-S102.

17. Solow, R. M., 1956, A Contribution to the Theory of Economic Growth, Quarterly Journal of Economics, 70(1), 65-94 